$\underline{\text { Review Article }}$

\title{
A REVIEW ON COVID-19-A GLOBAL BATTLE BETWEEN LIFE AND DEATH
}

\author{
CHITRA B. HANGARGEKAR ${ }^{1}$, RUBIYA S. QUAZI ${ }^{1}$, AMOL A. JOSHI ${ }^{2}$ \\ 1,2Department of Quality Assurance, ASPM's K. T. Patil College of Pharmacy, Osmanabad, 413501, Maharashtra, India, ${ }^{3}$ Department of \\ Pharmacognosy, ASPM's K. T. Patil College of Pharmacy, Osmanabad, 413501, Maharashtra, India \\ Email: chitra223753@gmail.com \\ Received: 17 Mar 2020, Revised and Accepted: 18 May 2020
}

\begin{abstract}
Currently, the globe is affected by a severe pandemic scenario of COVID-19 infection. The Covid-19 infectious disease is spreading everywhere on the globe particularly in developed countries like China, u. s. Italy, France, Spain, Iran, England, Germany, South Korea, etc. a deadly disease of a unique coronavirus (COVID-19 or 2019-CoV) infection has exhibited significant threats to global health, and also the economy. Following an outbreak of pneumonia without a transparent cause within the city of Wuhan in China, a novel strain of coronavirus (2019-nCoV) was detected in December 2019. Coronavirus is called for the spikes that protrude from their membranes just like the sun's corona. In line with WHO, Common signs of infection embrace fever, cold, cough, and respiratory difficulties like dyspnea, pneumonia. Within the absence of treatment for this virus, there's an imperative got to notice various strategies to manage the unfold of disease. It's "Corona time," however; unfortunately, it's the virus that we tend to speak. In this paper, the origin of the viral infection, the clinical characteristics of Covid-19, etiology, pathogenesis, symptoms treatment and hindrance of Covid-19 are comprehensively detailed. At the time of this writing there are more queries than answers. The aim of our article is to provide a comprehensive understanding of COVID-19 to the peoples, so they'll better understand it and prevent it.
\end{abstract}

Keywords: COVID-19, Dyspnea, Epidemic, Outbreak, Prevention, Wuhan

(C) 2020 The Authors. Published by Innovare Academic Sciences Pvt Ltd. This is an open access article under the CC BY license (http://creativecommons.org/licenses/by/4.0/) DOI: http://dx.doi.org/10.22159/ijcpr.2020v12i4.39084. Journal homepage: https://innovareacademics.in/journals/index.php/ijcpr

\section{INTRODUCTION}

Since December 2019, the outbreak of the 2019 novel coronavirus infection (COVID-19) infection has become a serious epidemic threat in China. A novel coronavirus, previously it had been designated as 2019-nCoV, and it had been known because the reason for a cluster of pneumonia cases found in Wuhan, a town within the Hubei Province of China, at the end of 2019. The primary reports of an unknown respiratory infection that was fatal some cases have emerged from Wuhan, China. The source of that infection was quickly known as a novel coronavirus, associated with people who had caused outbreaks of Severe Acute Respiratory Syndrome (SARS) from 2002-2004 and the Middle East Respiratory Syndrome (MERS) in 2012. The World Health Organization declared that the sickness resulting from the new virus, COVID-19, is a Public Health Emergency of international concern. It, later on, unfold throughout China and elsewhere, turning into a world health emergency. In February 2020, the World Health Organization (WHO) termed the disease COVID19, which stands for coronavirus disease 2019 [1].

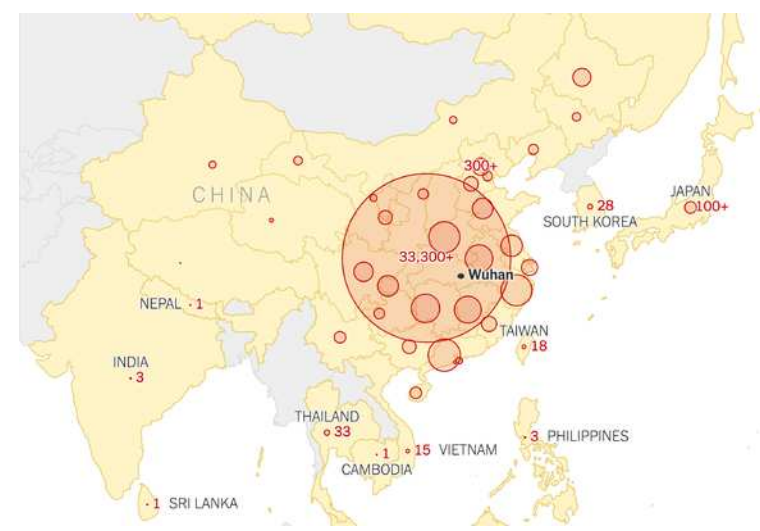

Fig. 1: The first reports of an unknown respiratory infection from Wuhan, China

\section{Structure of coronavirus}

Coronavirus is a novel virus belonging to a family coronaviridae. This family consists of single-stranded RNA viruses which have a lipid envelope decorated with club-shaped projections called corona means crown like that infects birds and many mammals including humans and that also includes the causative agents of MERS, SARS, and COVID-19. Coronaviruses are minute in size $65-125 \mathrm{~nm}$ in diameter) size ranging from 26 to $32 \mathrm{kbs}$ in length. The subgroups of coronaviruses family are alpha $(\alpha)$, beta $(\beta)$, gamma $(\gamma)$ and delta $(\delta)$ coronavirus. The human coronaviruses (HCoVs) comes in two of these genera: alpha coronaviruses (HCoV-229E and HCoV-NL63) and beta coronaviruses (HCoV-HKU1, HCoV-OC43, Middle East respiratory syndrome coronavirus [MERS-CoV], and the severe acute respiratory syndrome coronavirus [SARS-CoV] [2, 3]. The virion of coronavirus consists of a particle covered by an envelope which contains the spike (S), membrane (M), and envelope (E) proteins. Also, some strains of coronaviruses, but not SCoV, express 
a hem agglutinin protein (HE) that is also incorporated in the virion. The genome of coronaviruses is a linear, single-stranded RNA molecule of positive (mRNA) polarity, and from 28 to $32 \mathrm{~kb}$ in length within the virion, the genome is encapsidated by multiple copies of the nucleocapsid protein $(\mathrm{N})$ and has the conformation of a helical RNA/nucleocapsid structure $[4,5]$.
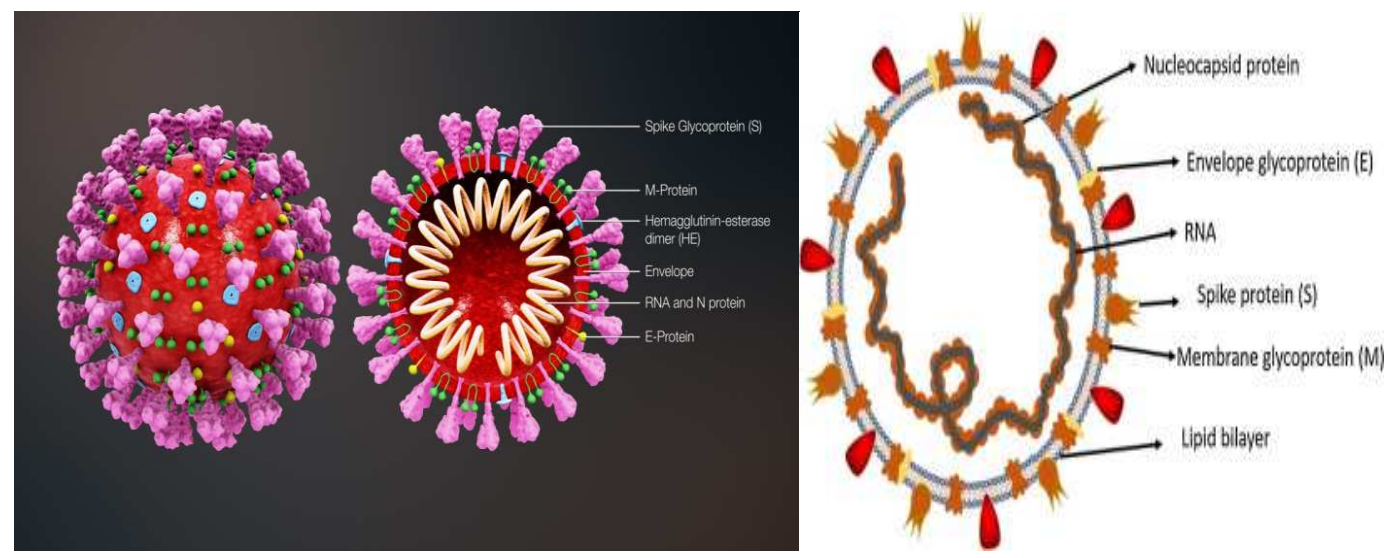

Fig. 2: Structure of 2019 novel coronavirus (2019-n-CoV)

\section{Viral composition}

Coronaviruses are medium-sized enveloped positive-stranded RNA viruses whose name derives from their characteristic crown-like look in electron micrographs $[6,7]$. The spikes on the periphery of the virus particles provide coronaviruses their name, crown-like. The researchers used a method referred to as cryo-electron microscopy to take detailed photos of the structure of the spike protein. This involves freezing virus particles and firing a stream of high-energy electrons through the sample to make tens of thousands of pictures. These pictures are then combined to yield an in-depth $3 \mathrm{D}$ view of the virus. The researchers found that the severe acute respiratory syndrome-CoV-2 spike was 10 to 20 times more likely to bind ACE2 on human cells than the spike from the SARS virus from 2002. This might change SARS-CoV-2 to unfold a lot of simply from person to person than the earlier virus [8].

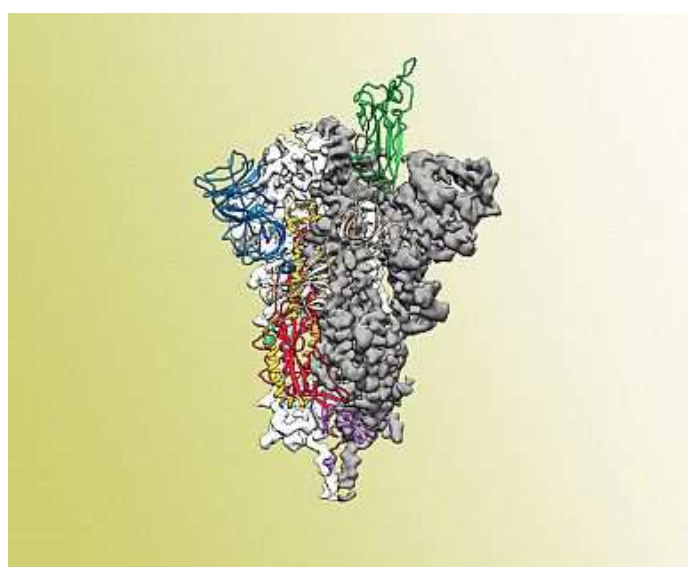

Fig. 3: Atomic-level structure of the SARS-CoV-2 spike protein. The receptor-binding domain, the part of the spike that binds to the host cell, is colored green

\section{The life cycle of corona virus}

The life cycle of SARS-CoV-2 in host cells; begins when S protein binds to the cellular receptor ACE2. Once receptor binding, the conformation modification within the $\mathrm{S}$ protein facilitates viral envelope fusion with the cytomembrane through the endosomal pathway. Then SARS-CoV-2 releases RNA into the host cell. Genome RNA is translated into viral replicase polyproteins pp1a and 1ab, which are then cleaved into little products by viral proteinases. The polymerase produces a series of subgenomic mRNAs by discontinuous transcription, and at last translated into relevant viral proteins. Viral proteins and genome RNA are subsequently assembled into virions within the ER and Golgi and so transported via vesicles and discharged out of the cell. ACE2, angiotensinconverting enzyme 2; ER, endoplasmic reticulum; ERGIC, ER-Golgi intermediate compartment [9].

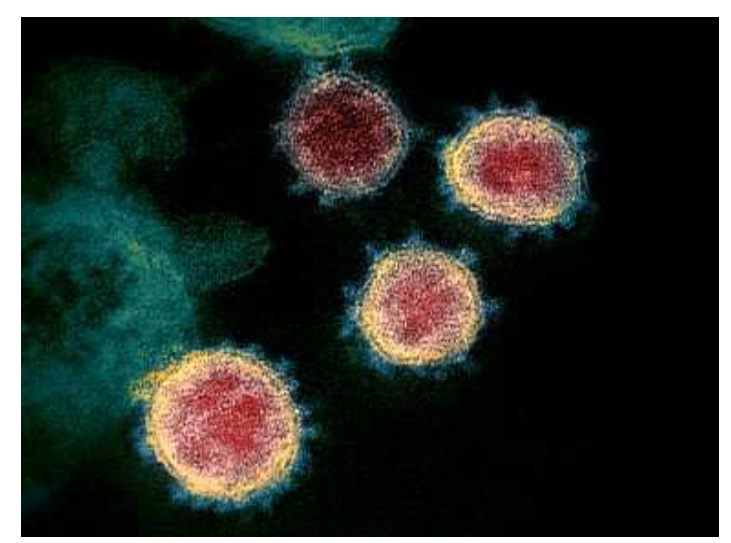

Fig. 4: Transmission electron microscope image shows SARSCoV-2, the virus that causes COVID-19

\section{Transmission}

The first cases of the Covid-19 disease were coupled to direct exposure to the Wuhan seafood Wholesale Market of Wuhan, that's why the animal-to-human transmission was likely because of the main mechanism. However, later cases weren't related to this exposure mechanism. Therefore, it was concluded that the virus might even be transmitted from human-to-human, and symptomatic individuals are the foremost frequent source of COVID-19 spread. The chance of transmission. Before symptoms develop looks to be occasional, though it can't be excluded. Moreover, there are some suggestions for those individuals who remain symptomless, they might additionally transmit the virus. This knowledge suggests that the utilization of isolation is the best way to manage this epidemic condition. Like respiratory metabolic process pathogens, including flu and rhinovirus, the transmission is believed to occur through respiratory droplets from coughing and sneezing. Aerosol transmission is additionally possible just in case of extended 
exposure to elevated aerosol concentrations in closed areas. Analysis of knowledge associated with the spread of SARS-CoV-2 in China looks to point that close contact between individuals could be the main source. The spread is primarily restricted to family members, healthcare professionals, and other close contacts [10]. Based on knowledge from the primary cases in Wuhan and investigations conducted by the China Center for Disease Control and Prevention and native CDCs, the incubation time could be usually inside 3 to $7 \mathrm{~d}$ and up to $2 \mathrm{w}$ as the longest time from infection to symptoms was $12.5 \mathrm{~d}$ [11]. This knowledge additionally showed that this novel epidemic condition doubled regarding every seven days, whereas the fundamental reproduction number $(\mathrm{R} 0-\mathrm{R}$ naught) is 2.2. In other words, on average, every patient transmits the infection to an additional 2.2 individuals.

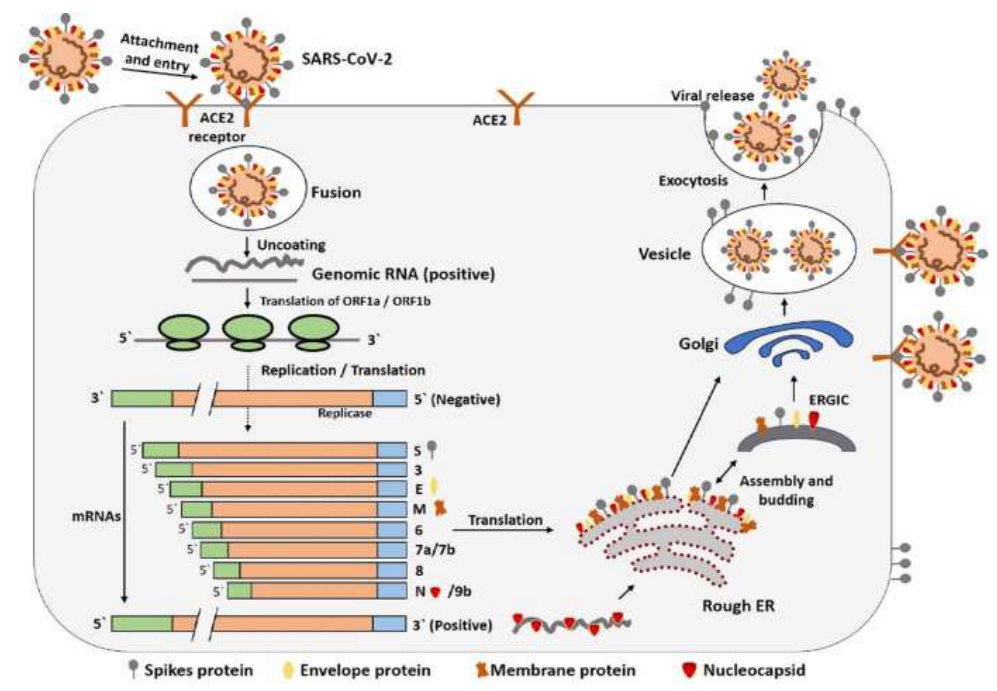

Fig. 5: Life cycle of 2019 novel coronavirus (2019-n-CoV)

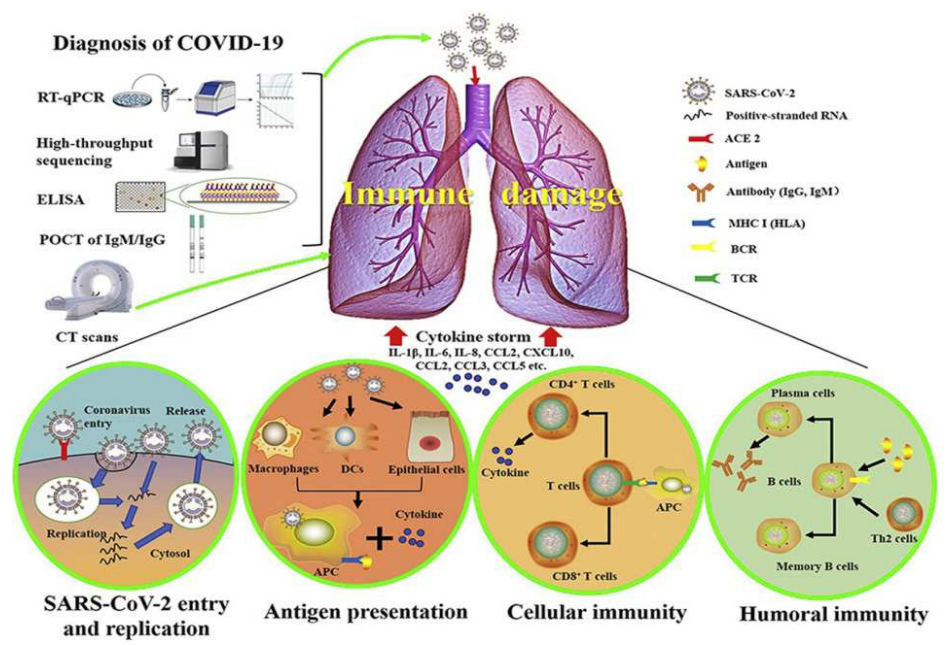

Fig. 6: Mechanism and diagnosis of 2019 novel coronavirus (2019-n-CoV) infection

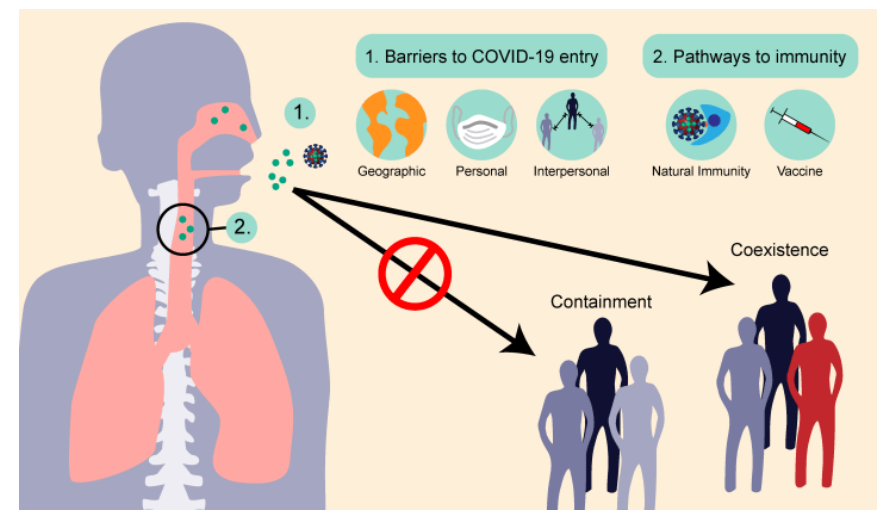

Fig. 7: Mode of transmission of COVID-19 
Here are various stages of the spread of the virus [12]

\section{Stage 1}

\section{Imported cases}

These are those cases that have traveled to virus-hit foreign countries and have come back to India.

\section{Stage 2}

Local transmission: These square measure those cases that have come in contact with patients who have a travel history.

\section{Stage 3}

Community transmission: Community transmission takes place when a patient who is not exposed to any infected person or who has not traveled to any of the affected areas, will test positive. Giant areas get is affected once community transmission takes place.

\section{Stage 4}

Epidemic: This is the last and worst stage where the disease takes the shape of an epidemic with no clear endpoint like it did in China and Italy.

\section{Symptoms}

The signs and symptoms of COVID-19 infection can be appear within two to $14 \mathrm{~d}$ after exposure to novel coronavirus and can include:

- Fever

- Cough

- Shortness of breath or difficulty breathing

Other symptoms can include:

- Tiredness

- Aches

- Runny nose

- Sore throat

The severity of symptoms of the infection can be ranges from very mild condition to severe condition. Some people have no symptoms. The older peoples or those persons who have existing chronic medical conditions, such as disease of heart or lung or if person suffering from diabetes and hypertension may be at higher risk of serious illness. This condition is similar to the condition which can be seen with other respiratory diseases, such as influenza.

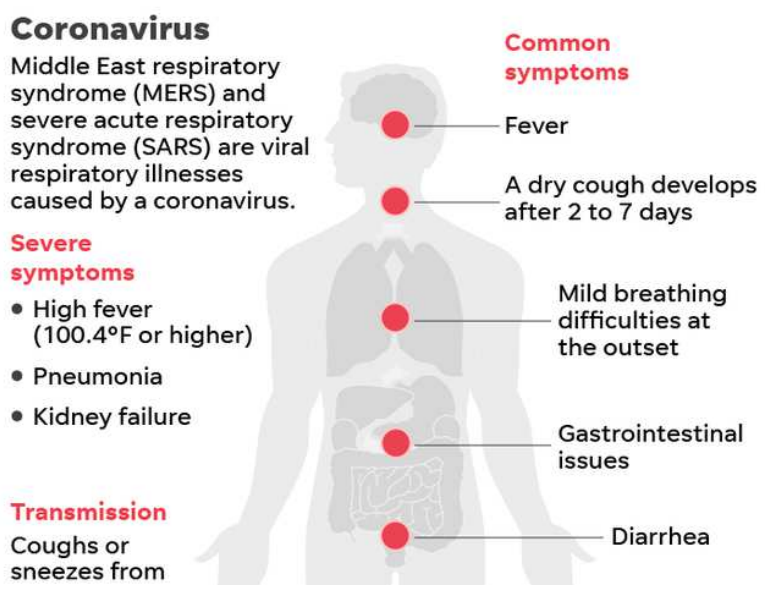

Fig. 8: Symptoms of COVID-19 infection

\section{Uncomplicated (mild) illness}

The patients of COVID-19 infection are usually present with symptoms of an upper respiratory tract viral infection, including mild fever, cough (dry), sore throat, nasal congestion, malaise, headache, muscle pain. Signs and symptoms of a more serious disease, like dyspnea, are not present. Compared to previous HCoV infections, non-respiratory symptoms such as diarrhea are difficult to find in these cases.

\section{Moderate pneumonia}

Respiratory symptoms like cough and shortness of breath (or tachypnea in children) are present without signs of severe pneumonia.

\section{Severe pneumonia}

Fever is associated with severe dyspnea, respiratory distress, tachypnea ( $>30$ breaths/min), and hypoxia ( $\mathrm{SpO} 2<90 \%$ on room air). However, the fever symptom must be interpreted carefully as even in severe forms of the disease, it can be moderate or may be absent. Cyanosis can occur in children. In this definition, the diagnosis is clinical, and radiologic imaging is employed for excluding complications.

\section{Initial assessment of a patient}

Some clues will hint at a COVID-19 infection.
Location: there will be different probabilities of infection for people living in different places. People near the epicenter are more likely to be infected. People living near popular tourist destinations are more likely to be infected than people from isolated places like rural Alaska.

Travel history: travelers from places near the epicenter or other outbreak locations are more likely to have the infection (hence, why travelers are screened).

Social contacts: people who have close contact with the infected/those at risk of infection are more likely to be infected themselves.

Symptoms: People who have symptoms characteristic of coronaviruses, such as fever, cough, and shortness of breath are more likely to be infected.

Imaging: people who show imaging features of coronavirus on an $\mathrm{x}$ ray or CT scan are more likely to be infected.

\section{Diagnosis [13]}

If someone develops symptoms of coronavirus infection (COVID-19) and if that person has-been exposed to the virus, then that person should contactto the doctor. He/she should explain details of travelling if he/she traveled to any areas with ongoing community outbreak of COVID-19 according to CDC and WHO. He/she should 
also inform to doctor if he/she had close contact with anyone who has been diagnosed with COVID-19. After knowing details, the doctor may determine whether to conduct tests for COVID-19 based on signs and symptoms of that person or not. Doctor will decide whether to conduct tests for COVID-19 by considering whether he/she have had close contact with someone diagnosed with COVID19 or traveled to or lived in any areas with continuing community outbreak of COVID-19 infection in the last $14 \mathrm{~d}$. The doctor may take specific samples, including a sample of saliva (sputum), a nasal swab and a throat swab, to send to a lab for testing of COVID-19.

\section{How it spreads?}

COVID-19 infection is flu like; it can be spread from one person to another person. When a person infected with COVID-19 infection coughs, sneezes or talks, they may spread droplets containing the virus at a short distance, which quickly settles on the surrounding surfaces. One may get infected by the virus if that person touches those surfaces or objects and then touch his/her mouth, nose or eyes. That's why it's really important to use good hygiene, regularly wash the hands with good sanitizer and thoroughly dry the hands, and use good coughing and sneezing etiquette.

\section{Prevention-how to protect yourself and others}

- Try to cough or sneeze into your elbow or cover your mouth and nose with tissues or disposable mask while coughing and sneezing.

- Put the used tissues or disposable masks in the dustbin or a bag immediately.

- Avoid large social events and mass gatherings and keep social distance.

- Frequently wash your hands with good soap or sanitizer and water (for at least 20 seconds).
- Try to avoid close contact (about 6 feet) with unwell people.

- Don't touch to your eyes, nose or mouth unless and until your hands are not going to be cleaned.

- Avoid personal contact, such as hand shaking, sharing cups, glass or food with sick people.

- Clean and disinfect frequently touched surface areas and objects, such as doorknobs and other metallic objects.

- Stay home if you feel unwell. Try to do work from home, avoid public areas if you're sick unless you're going to get medical care. Avoid taking public transportation if you're sick.

- Call Health line if you have any symptoms and have been travelled to any other country having ongoing outbreak or have been in close contact with someone confirmed with COVID-19.

- Self-isolation is a major and possible prevention for coronavirus infection.

What to do if you may have been exposed to COVID-19 infection?

- People returning from any country, or who may have been exposed to COVID-19, are self-isolating to keep their communities safe.

- If you returned from any country in the last $14 \mathrm{~d}$, then you should self-isolate for $14 \mathrm{~d}$ from the date of departure.

- If you have been came in close contact with a confirmed case of COVID-19 you should self-isolate for $14 \mathrm{~d}$ from the date of close contact.

- Self-isolation is effective way, and most people are good at keeping themselves and others safe and well.

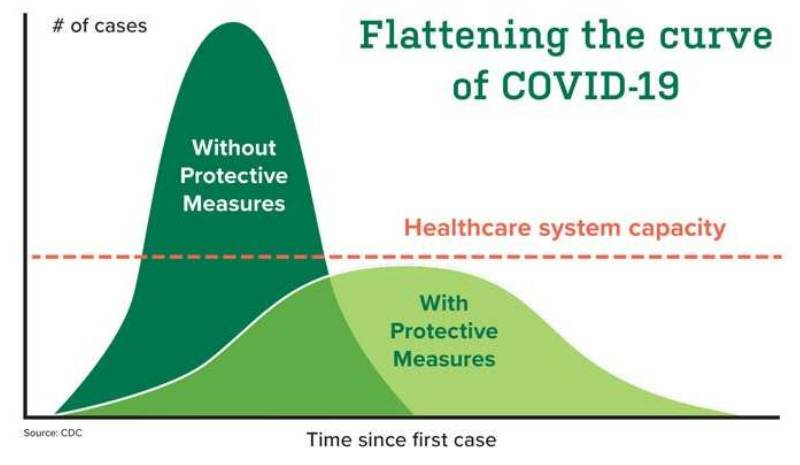

Fig. 9: Flattening the curve of COVID-19

\section{Treatment/Management}

There is no specific antiviral treatment recommended for COVID-19, and no vaccine is currently available. Several antivirals and other agents like antimalerials, antis wine flue drugs were used during the severe acute respiratory syndrome coronavirus (SARS-CoV) outbreak, but the efficacy of these drugs has not been established. Chloroquine and hydroxychloroquine can be used for initial symptoms [16]. However, there have been no studies of efficacy in severe conditions. People infected with COVID-19 should receive supportive care to relieve the symptoms of infection. In severe cases, treatment should contain care to support vital organ functions. The treatment is symptomatic, and oxygen therapy represents the major treatment intervention for patients with severe infection. Mechanical ventilation may be necessary in cases of respiratory failure refractory to oxygen therapy, whereas hemodynamic support is essential for managing septic shock. Till date there is no any specific medicine to prevent or to treat coronavirus disease (COVID19). People may need supportive care like artificial ventilators to help them breathe. Preventive measures consist of hand washing and the careful disposal of materials infected with nasal and salivary secretions. The use of surface disinfectants is also an important issue in infection measures since coronaviruses appear to survive for one or more days after drying on surfaces such as stainless steel, metals, plastic, or cloth [17].

\section{Self-care}

WHO recommends that you:

- Health authority like CDC doesn't recommend that healthy people should wear a face mask to protect themselves from COVID19 infection. Only wear a mask if your doctor tells you to do so.

- Avoid eating raw or undercooked food materials like meat or animal organs.

- Avoid close contact with live pet animals and surfaces; they may have touched if you're visiting live markets in areas that have recently had new coronavirus cases.

- If you have a chronic medical condition and if you have a higher risk of serious illness, checkup yourself by the doctor and know about other ways to protect yourself. 
- If you're planning to travel internationally, first check the government websites for updates and advice. Also, look for any health advisories that may be in a place where you plan to travel. You can also talk with your doctor if you have health conditions that make you more susceptible to respiratory infections and complications.

- If you have mild symptoms, stay at home until you have been fully recovered. You can relieve your symptoms if you:

1. Rest and sleep properly for 6-8 h.

2. Take the help of yoga and meditation for mental peace.

3. Keep warm and clean the surrounding area.

4. Drink plenty of liquids. (Usually 2-3 lit water, fresh fruit juices etc.)

5. Avoid cold drinks and stuffs (eg. Ice-cream, preserved soft-drinks)

6. Use a room humidifier or take a hot shower to help ease a sore throat and cough.

7. Stop listening and spreading rumors.
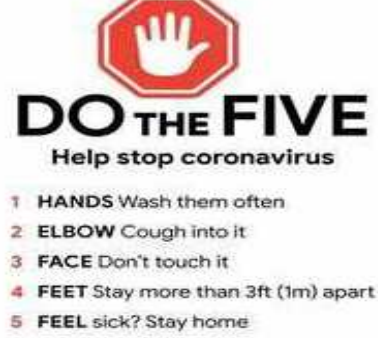

Fig. 10: Five steps for prevention of COVID-19 infection

\section{CONCLUSION}

In conclusion, the occurrence and development of SARS-CoV-2 depend on the interaction between the virus and the individual's immune system. As the COVID-19 epidemic continues to spread around the world, we need to plan and prepare ourselves proactively. Providing appropriate clinical management and support to patients while adequately protecting healthcare professionals should be our goal. Novel coronavirus itself is not a new virus. It is believed to have been living peacefully in its host bats, the mammal cousins of humans. Sometimes in November last year, this novel coronavirus, now official named SARS-COV-2 or severe acute respiratory syndrome coronavirus- 2 made the journey from bats through some intermediary animal to humans in the Chinese business hub of Wuhan. Now novel coronavirus is a human virus and it is a new virus for the human body. The novel coronavirus being new means the body does not know the mechanism of how to fight this unknown enemy it also means there is no readily available medicine to neutralize novel coronavirus in the human body. The individual's immune system factors include genetics (such as HLA genes), age, gender, nutritional status, neuroendocrine-immune regulation, and physical status. These factors all contribute to whether an individual is infected with the virus, the duration and severity of the disease, and the reinfection. Now a day this situation poses a serious public health risk. The government of nation is working closely with state, local, tribal, and territorial partners, as well as public health partners, to respond to this situation. In these times of crisis all communities should come together even more to support for the global efforts in diagnosis, treatment, prevention and further research in this disease and similar viral respiratory infections. Our approach is to utilize the available world-class information that we have to directly improve health and to support the virtual efforts of healthcare practitioners globally.

\section{ACKNOWLEDGMENT}

The authors wish to thank all the participants in this study. We sincerely thank the individuals who contributed to this work including all our colleagues, management and Principal of ASPM's K. T. Patil College of Pharmacy, Osmanabad. We would like to wish a special thanks to Mohammad Sadat Khan and Pramod Vighne and Prashant Chavan.

\section{FUNDING}

Nil

\section{AUTHORS CONTRIBUTIONS}

All the authors have contributed equally.

\section{CONFLICTS OF INTERESTS}

The authors declare that there are no conflicts of interest.

\section{REFERENCES}

1. https://www.who.int/dg/speeches/detail/who-directorgeneral-s-remarks-at-the-media-briefing. [Last accessed on 11 Feb 2019]

2. Chan JF, Lau SK, To KK. Middle East respiratory syndrome coronavirus: another zoonotic betacoronavirus causing SARSlike disease. Clin Microbiol Rev 2015;28:465.

3. http://ictvonline.org/virusTaxonomy.asp [Last accessed on 02 Mar 2015]

4. Bonilla PJ, Gorbalenya AE, Weiss SR. Mouse hepatitis virus strain A59 RNA polymerase gene ORF 1a: heterogeneity among MHV strains. Virology 1994;198:736-40.

5. Anand K, Ziebuhr J, Wadhwani P, Mesters JR, Hilgenfeld R. Coronavirus main proteinase (3CLpro) structure: basis for the design of anti-SARS drugs. Science 2003;300:1763-7.

6. Commentary: McIntosh K, Chao RK, Krause HE, Wasil R, Mocega HE, Mufson MA. Coronavirus infection in acute lower respiratory tract disease of infants. J Infect Dis 2004;190:1033-5.

7. Masters PS, Perlman S. Coronaviridae. In: Fields Virology. 6th ed. Knipe DM, Howley PM, Cohen JI. et al. (Eds). Vol. 2. Lippincott Williams and Wilkins, a Wolters Kluwer business, Philadelphia; 2013. p. 825.

8. https://www.nih.gov/news-events/nih-researchmatters/novel-coronavirus-structure-reveals-targets-vaccinestreatments [Last accessed on 03 Mar 2020]

9. Adnan Shereen M, Khan S, Kazmi A, Bashir N, Siddique R. COVID-19 infection: origin, transmission, and characteristics of human coronaviruses. J Adv Res 2020;1:25.

10. Perlman S, Netland J. Coronaviruses post-SARS: update on replication and pathogenesis. Nat Rev Microbiol 2009;7:439-50.

11. Li Q, Guan X, Wu P, Wang X. Early transmission dynamics in wuhan, china, of novel coronavirus-infected pneumonia. N Engl J Med 2020;382:1199-207.

12. https://english.jagran.com/india/coronavirus-outbreak-indiain-stage-2-of-covid19-transmission-a-look-at-four-stages-ofvirus-spread-10009781 [Last accessed on 21 Mar 2020]

13. https://www.mayoclinic.org/diseases-conditions/ coronavirus/diagnosis-treatment/drc-20479976 [Last accessed on 20 Dec 2019]

14. Keyaerts E, Vijgen L, Maes P. In vitro inhibition of severe acute respiratory syndrome coronavirus by chloroquine. Biochem Biophys Res Commun 2004;323:264.

15. Kono M, Tatsumi K, Imai AM. Inhibition of human coronavirus 229E infection in human epithelial lung cells (L132) by chloroquine: involvement of p38 MAPK and ERK. Antiviral Res 2008;77:150.

16. Keyaerts E, Li S, Vijgen L. Antiviral activity of chloroquine against human coronavirus OC43 infection in newborn mice. Antimicrob Agents Chemother 2009;53:3416.

17. Otter JA, Donskey C, Yezli S. Transmission of SARS and MERS coronaviruses and influenza virus in healthcare settings: the possible role of dry surface contamination. J Hosp Infect 2016;92:235.

18. https://www.who.int/emergencies/diseases/novelcoronavirus-2019/technical-guidance/infection-preventionand-control [Last accessed on 19 Mar 2020] 